\title{
Possibilities of using virtual reality as a means for therapy from fear of spiders
}

\author{
Miroslav Musalek ${ }^{1 *}$ and Lubomir Vasek $^{1}$ \\ ${ }^{1}$ Tomas Bata University - Faculty of Applied Informatics, Nad Stranemi 4511, Zlin, 760 05, Czech Republic
}

\begin{abstract}
The subject of this article is to find out whether virtual reality can affect phobia of spiders. For this pre-research were performed 20 experiments on a small sample of subjects. Two approaches were used to measure during the experiments. The values of results are represented by this post.
\end{abstract}

\section{Introduction}

This pre-research is aimed at exploring the possibilities of using virtual reality (VR) for therapy in people suffering from spider fear.

The concept of virtual reality (VR) first appeared in 1986 [1]. The VR is a way to simulate reality for the user through his senses. The resulting product should be an artificially created environment that gives the user a sense of being present in the virtual environment. This is achieved through sensory stimulation, approaching the real experience to the point that the user does not distinguish reality from virtual reality.

Contemporary technology of virtual reality uses the principle of shielding signals coming from the real world and tries to replace these removed perceptions with artificial perceptions [2]. Therefore, the standard equipment of VR equipment is a device projecting the image directly in front of the user, so that it only stays in contact with that projection and any other visual stimuli are shielded. The same procedure also works with audio signals. Therefore, headphones are often used to simulate different directions of sound sources. An important component for VR is also a motion sensor that allows the user to move around the virtual environment. This also involves hand movement tracking to ensure the ability to interact with the environment. The user is normally equipped with drivers that allow this interaction. Merriam-Webster dictionary defines VR as [3]:

"An artificial environment which is experienced through sensory stimuli (such as sights and sounds) provided by a computer and in which one's actions partially determine what happens in the environment"

A more detailed description of the virtual environment, its division, and its possibilities are in the paper [4]. In addition to virtual reality, there is also Augmented reality (AR). In the sense of focusing this pre-research, the use of this technology has not been found.

Authors in the paper [5] made five sessions which helped to improve the investigation 28 adults to behave in the presence of spiders.

In the article [6] explored the possibilities of using customized 3D computer games. Participants were 10 women and 1 man. Valve Corporation's Half-Life game was modified here. This approach has proved successful.

In the article [7] compared the effectiveness of VR exposure vs. a waiting list condition. This research showed that VR exposure was more effective than waiting list features phobia.

Michaliszyn et al. [8] assessed the effects of the virtual environment after a three-month exposure in the VR environment. Participants received eight 1.5 -hour treatment sessions. The VR approach had promising results.

Shiban et al. [9-11] demonstrated the possibilities and success of using VR technology in a controlled environment during different conditions. In these studies, virtual reality has proven to be a capable means in the treatment of spider fear.

\subsection{Phobia}

Phobia is described as an exaggerated irrational fear of a particular object. This fear is so significant that it interferes with the daily life of the individual. Praško defines phobia as [12]:

\footnotetext{
"We define phobia as a permanent and excessive fear of a certain object or situation that is not really dangerous. This fear leads to an intense desire to avoid phobic situations, even though phobic people often recognize that it is not rational."
}

\footnotetext{
Corresponding author: $\underline{\text { musalek@utb.cz }}$
} 
Fear and anxiety are otherwise normal and mostly useful states for man, helping to avoid dangerous situations and respond to them when they occur. Phobia, in relation to fear, can limit a person in everyday life. This can lead to a tendency to avoid certain situations or places. Everyone tolerates phobias individually.

The typical components of the state of the phobia [12]:

- Typical bodily anxiety symptoms

- Feared thoughts

- Avoiding the stimulus that causes fear

\subsubsection{Phobia of spiders}

The fear of spiders is also known as Arachnophobia. The word Arachnophobia is derived from the Greek word 'Arachne' meaning spiders.

Arachnophobia is a diseased, anxious, insurmountable to panic fear of spiders, classified as a psychiatric anxiety disorder called phobia. A man suffering from arachnophobia is aware of his problem and may also feel absurd and irrational to him, such as people from his surroundings or family.

People with arachnophobia refuses to voluntarily expose itself to the slightest risk of coming into contact with the object of its fear - the spider. He does not go to the cellars or to the attic. Such a person is very nervous just looking at spider webs.

As with other phobias, arachnophobia can develop in a person because she sees the reaction to spiders of others with the phobia. Another cause may be a traumatic experience with a spider in childhood. Especially if a spider bit a kid. Another option may be cultural subtext.

The initial phobia may occur in childhood or adulthood. An unpleasant encounter with a spider can cause many symptoms [13]:

- Rapid heart rate

- Dizziness

- Hot or cold flashes

- A feeling of going crazy and losing control

- Chest pain

- Feeling of choking

- Inability to distinguish between reality and unreality

- Trembling sweating

- Thoughts of death

- Nausea or other gastrointestinal distress

Therapeutic sessions, meditation or medication treatment are used to overcome the phobia.

\section{Material and methods}

\subsection{Used virtual reality}

Virtual reality creates a simulation of the real environment we perceive with our senses. This virtual environment is created with a hardware solution along with appropriate software that is subsequently projected to a special headset. For this pre-research was used headset HTC Vive Pro (Fig. 1).

A brief description of used headset: The HTC Vive Pro virtual reality system consists of several parts which represent a whole virtual experience. It includes a pair of integrated AMOLED displays (3.5 "diagonal) with a resolution of $2880 \times 1600$ pixels and a Field Of View (FOV) 110-degree. In addition, the headset provides surround sound through integrated headphones. Transferring information between the headset and the computer is via the Link Box. Controlling the virtual environment settings and interacting with objects in the VR environment is enabled through two Controllers for each hand. They contain motion sensors and control buttons, where the most important button for most actions is the trigger. There are two base stations (not in picture) that help to create presence and immersion of room-scale virtual reality by helping the VIVE headset and controllers track their exact locations [14].

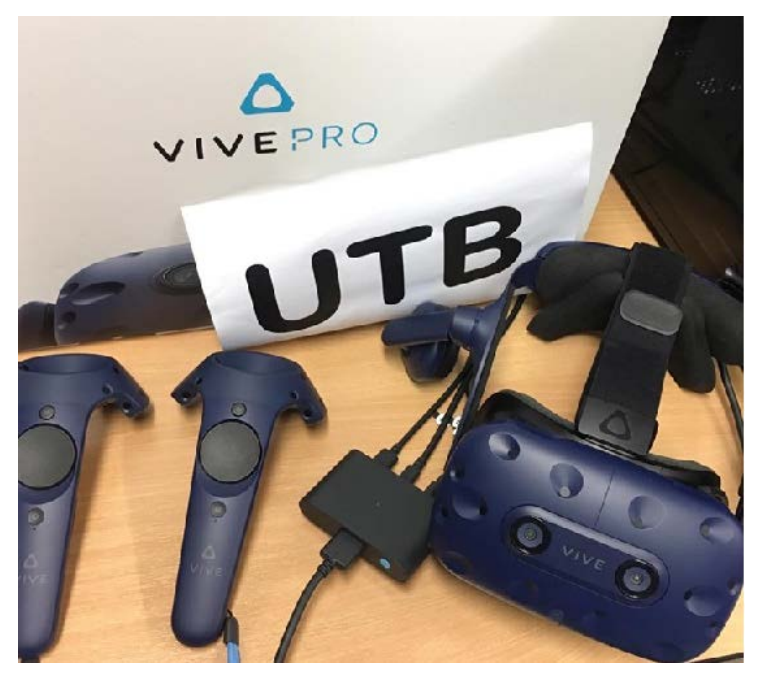

Fig. 1. HTC Vive Pro components.

This HTC headset needs a powerful computer, especially a graphics card. Used computer was composed of CPU AMD Ryzen 7 2700X 3.7 GHz, GPU NVIDIA GeForce GTX 1080 Ti 11GB, ASUS PRIME X470-PRO (motherboard), RAM 16GB $3000 \mathrm{MHz}$, SSD 500GB + HDD 2000GB with Windows 10 64-bit.

\subsection{Procedures and methods of measurement}

The pre-research process involved 20 virtual reality sessions. The goal was to expose participants to phobia from spiders in the virtual world through the HTC Vive Pro headset. The user stayed in the VR environment as long as the time until one of the causes of phobia showed up. The whole process of exposure, rest and evaluation of the VR environment is shown in Fig. 2. 


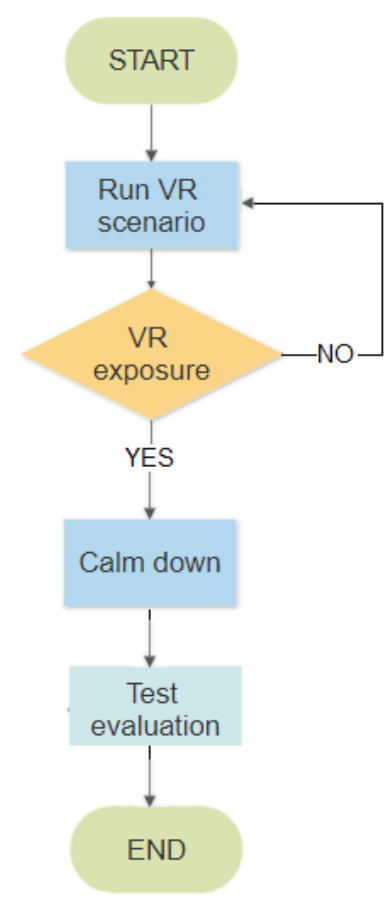

Fig. 2. Flowchart of VR phobia therapy.

As shown in the scheme, there is resting interphase between measurements after VR therapy. This a part of the whole VR therapy process took 15 minutes. Its purpose was to relax the user and induce pleasant feelings.

\section{Measuring the experiment}

During this pre-research, people were exposed to the presence of a spider in virtual reality. Three distances of the person from the table on which the spider was given were set. Specifically on 5 meters, 10 meters, and 15 meters. During one session, the person was exposed to all three distances. The goal was to measure the time until the user experiences phobia symptoms and the headset will need to be removed. This time was measured in minutes.

A questionnaire was used to evaluate participants' feelings Severity Measure for Specific Phobia-Adult (SMSP-A) created by the American Psychiatric Association [15] which consists of 10 questions. Each item on the measure is rated on a 5 -point scale $(0=$ Never; $1=$ Occasionally; $2=$ Half of the time; $3=$ Most of the time, and $4=$ All of the time). A total score of 0 to 40 points can be achieved in this test. All questions (10) need not be completed. The resulting score is the ratio of the total number of questions (10) to the number of answers. This questionnaire was used for the first session, the fifth, the tenth, the fifteenth, and the last twentieth session.
The resulting score for each session is the sum of the individual elements that serve as an indicator of the effect of therapy in the virtual environment.

\section{Results and discussions}

The idea has been created whether therapy in virtual reality can have an effect on the phobia of spiders. The pre-research was implemented at the Faculty of Applied Informatics at Tomas Bata University in Zlin on a small sample of respondents.

The experiment worked with two people afraid of spiders. They had a phobia from spiders even they just imagined them. Their heart rate increased and they had hot flashes.

Phobia manifestations can cause limitations in these people's daily lives. For the fear of meeting a spider or even having a direct touch or bite, people give up some options in their lives. Above all, it is about avoiding certain places or situations.

The pre-research works with the simulation of the VR environment with the occurrence of a spider. The main purpose is to expose itself to an unpleasant situation and thereby to strengthen the user. Basic information about the people involved in the preresearch can be seen in Table 1 .

Table 1. Overview of general data of the people involved in the pre-research.

\begin{tabular}{|l|l|l|}
\hline & User 1 & User 2 \\
\hline Gender & Male & Male \\
\hline Age & 25 & 30 \\
\hline Level of education & $\begin{array}{l}\text { High } \\
\text { School }\end{array}$ & University \\
\hline First phobia situation & Childhood & 2010 \\
\hline
\end{tabular}

The pre-research was conducted as follows: Both users have a moderate phobia of spiders. Each of them started at 15 meters and time was measured until the time of one of the phobia symptoms and then removing the headset. The same approach was applied to 10 and 5 meters.

At the first, fifth, tenth, fifteenth and twentieth session of the pre-research, all the users underwent the same process, during which they filled in tests measuring their level of phobia (SMSP-A). The results of the first measurement step are shown in Table 2 (User 1) and in Table 3 (User 2).

Table 2. User 1 VR therapy measuring. 


\begin{tabular}{|c|c|c|c|c|c|c|}
\hline & & $\begin{array}{l}\text { Time per } \\
\text { session } 1\end{array}$ & $\begin{array}{l}\text { Time per } \\
\text { session } 5\end{array}$ & $\begin{array}{l}\text { Time per } \\
\text { session } 10\end{array}$ & $\begin{array}{l}\text { Time per } \\
\text { session } 15\end{array}$ & $\begin{array}{l}\text { Time per } \\
\text { session } 20\end{array}$ \\
\hline \multirow{3}{*}{ 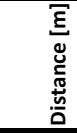 } & 15 & 5 & 5,833 & 6,4 & 7 & 10 \\
\hline & 10 & 3 & 4,1 & 4,683 & 5,367 & 6,967 \\
\hline & 5 & 0,5 & 0,833 & 1,133 & 2 & 2,933 \\
\hline \multicolumn{2}{|c|}{ Total score per session } & 38,5 & 40,816 & 42,216 & 44,367 & 49,9 \\
\hline
\end{tabular}

Table 3. User 2 VR therapy measuring.

\begin{tabular}{|c|c|c|c|c|c|c|}
\hline & & $\begin{array}{l}\text { Time per } \\
\text { session 1 }\end{array}$ & $\begin{array}{l}\text { Time per } \\
\text { session } 5\end{array}$ & $\begin{array}{c}\text { Time per } \\
\text { session } 10\end{array}$ & $\begin{array}{l}\text { Time per } \\
\text { session } 15\end{array}$ & $\begin{array}{c}\text { Time per } \\
\text { session } 20\end{array}$ \\
\hline \multirow{3}{*}{ 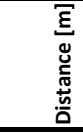 } & 15 & 4,5 & 5,917 & 6,867 & 8,867 & 14 \\
\hline & 10 & 2,917 & 4,25 & 6,067 & 7,17 & 8,133 \\
\hline & 5 & 0,75 & 1,867 & 3,083 & 4,15 & 5,25 \\
\hline \multicolumn{2}{|c|}{ Total score per session } & 38,167 & 42,034 & 46,017 & 50,187 & 57,383 \\
\hline
\end{tabular}

The total score for each season is composed of partial calculations. Each individual distance is summed with a given value of the measured time. This approach is the result of the therapy's score in the virtual environment.

The results of the measurements show that the therapy on the phobia from the spiders has a positive effect by virtual reality.

For the better orientation of the results, their graphic form is used in the form of a graph depicted in Fig. 3.

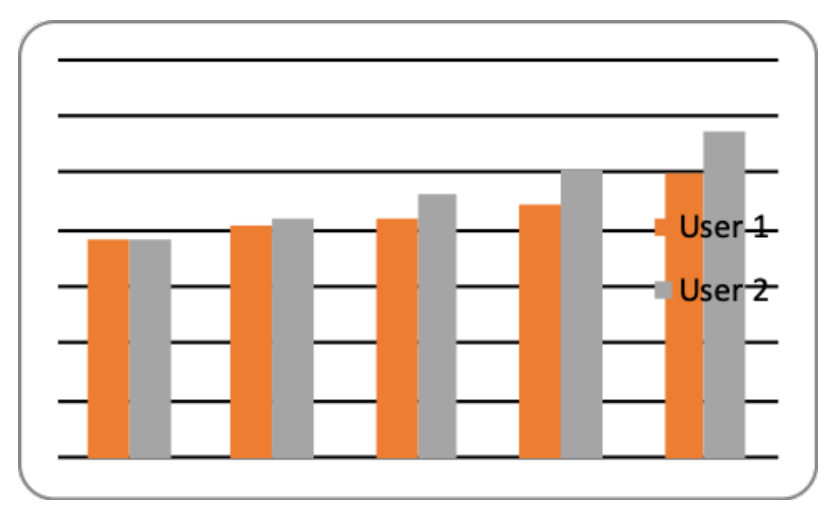

Fig. 3. Comparison of results during sessions in VR.

These data represent possibilities and positive improvements. We can see that the improvement is not entirely linear. It is to a certain extent caused by the individual's individual possibilities when everyone reacts differently.

\section{Severity Measure for Specific Phobia}

This test consists of 10 questions. The point values of both therapy users in the virtual environment are displayed in Table 4.
Table 4. Survey results for virtual reality therapy.

\begin{tabular}{|c|c|c|c|c|c|}
\hline $\begin{array}{c}\text { Number of } \\
\text { session }\end{array}$ & $\mathbf{1}$ & $\mathbf{5}$ & $\mathbf{1 0}$ & $\mathbf{1 5}$ & $\mathbf{2 0}$ \\
\hline User $\mathbf{1}$ & 21 & 20 & 18 & 17 & 15 \\
\hline User $\mathbf{2}$ & 20 & 18 & 17 & 15 & 14 \\
\hline
\end{tabular}

The results of the survey are the result of a set of questions after measured sessions at the end of virtual reality therapy. Above all, these are subjective feelings and perceptions of the situation.

Out of total assessment is based on promising results from the VR therapy. The measured data and the evaluated data represent a possible positive impact of the effects of virtual reality on the phobia from spiders. Moreover, these data are supported by a structured phobia questionnaire in a positive way.

\section{Conclusion}

The primary aim of the pre-research was to determine whether virtual reality can be used as part of therapy for people with a phobia of spiders. These phobias can disturb their lives.

The measurement of this pre-research was carried out on two persons with moderate phobia from spiders. A total of 20 sessions were performed. Here, the distance and the time at which the user reaches one of the phobic signs was evaluated. This measurement was accompanied by a structured phobia questionnaire. The results of this pre-research show that virtual reality therapies are beneficial.

This approach has some limiting factors. A small group of people is a limiting factor in this pre-research. Although virtual reality has been shown to be positively evaluated in the therapy of phobia from spiders, more testing will be needed.

Further testing of a virtual person approach should include more variables. Variants with more spiders can be included here. Next, add the movement of the spiders in the created environment. For phobia sufferers already looking at cobwebs, simulations could be created starting at this level. In particular, current trends use a limited number of sensory perceptions. A new trend for future research will be the use of haptic gloves coupled to a real spider model with the same projection in a virtual environment.

There was a help for this research by grant no. IGA/CebiaTech/2019/003 from Tomas Bata University in Zlin.

\section{References}

[1] Riva, G. (2005). Virtual reality in psychotherapy. Cyberpsychology \& behavior, 8(3),220-230.

[2] Muhanna, M. A. (2015). Virtual reality and the CAVE: Taxonomy, interaction challenges and research directions. Journal of King Saud University-Computer and Information Sciences, 27(3), 344-361. 
[3] Virtual reality. Merriam-Webster [online]. Available: https://www.merriamwebster.com/dictionary/virtual $\% 20$ reality

[4] Alraizzah, Asmaa \& Lamya, Foaud \& Fattouh, Lamia. (2017). Environments and System Types of Virtual Reality Technology in STEM: A Survey. IJACSA. 8. 10.14569/IJACSA.2017.080610.

[5] [Côté S, Bouchard S. Documenting the efficacy of virtual reality exposure with psychophysiological and information processing measures. Appl Psychophysiol Biofeedback. (2005);30:217-232. doi: 10.1007/s10484005-6379-x.

[6] Bouchard S, Côté S, St-Jacques J, Robillard G, Renaud P. Effectiveness of virtual reality exposure in the treatment of arachnophobia using $3 D$ games. Technol Health Care. (2006);14:19-27.

[7] Garcia-Palacios, Azucena \& G. Hoffman, H \& Carlin, Albert \& Furness, Thomas \& Botella, Cristina. (2002). Virtual reality in the treatment of spider phobia: A controlled study. Behaviour research and therapy. 40. 983-93. 10.1016/S0005-7967(01)00068-7.

[8] Michaliszyn D, Marchand A, Bouchard S, Martel MO, Poirier-Bisson J. A randomized, controlled clinical trial of in virtuo and in vivo exposure for spider phobia. Cyberpsychol Behav Social Netw. (2010);13:689-695. doi: 10.1089/cyber.2009.0277.

[9] Shiban Y, Pauli P, Mühlberger A. Effect of multiple context exposure on renewal in spider phobia. Behav Res Ther. (2013);51:68-74. doi: 10.1016/j.brat.2012.10.007.

[10] Shiban Y, Brütting J, Pauli P, Mühlberger A. Fear reactivation prior to exposure therapy: does it facilitate the effects of VR exposure in a randomized clinical sample? J Behav Ther Exp Psychiatry. (2015);46:133140. doi: 10.1016/j.jbtep.2014.09.009.

[11] Shiban Y, Schelhorn I, Pauli P, Mühlberger A. Effect of combined multiple contexts and multiple stimuli exposure in spider phobia: a randomized clinical trial in virtual reality. Behav Res Ther. (2015);71:45-53. doi: 10.1016/j.brat.2015.05.014.

[12] J. Praško, H. Prašková and J. Prašková. Specific phobias. Prague: Portal, (2008). Health Advisors.

[13] Fear of Spiders Phobia - Arachnophobia. Fearof. Available: https://www.fearof.net/fear-of-spidersphobia-arachnophobia/

[14] VIVE Pro. Vive. Available: https://www.vive.com/us/product/vive-pro/

[15] Severity Measure for Specific Phobia - Adult. APA Publishing. Available: https://www.psychiatry.org/ 